\title{
POTENCIAL FISIOLÓGICO EM SEMENTES DE CULTIVARES DE FEIJÃO CRIOULO (Phaseolus vulgaris L.) ${ }^{1}$
}

\author{
CILEIDE MARIA MEDEIROS COELHO², MURILO RENAN MOTA², \\ CLOVIS ARRUDA SOUZA4 ${ }^{4}$ DAVID JOSÉ MIQUELLUTI ${ }^{5}$
}

\begin{abstract}
RESUMO - O trabalho foi realizado com o objetivo de caracterizar genótipos crioulos quanto ao potencial fisiológico das sementes. As sementes foram obtidas na safra 2007/2008, com 26 genótipos, no município de Lages - SC. Para analisar a qualidade das sementes, determinou-se o porcentual de germinação inicial e após o envelhecimento acelerado, massa de 100 sementes, condutividade elétrica, comprimento da raiz primária e emergência a campo. Os genótipos foram separados em classes com base no teste Scott-Knott e os genótipos crioulos também foram comparados com a testemunha (cultivares comerciais) pelo teste de Dunnett, os quais permitiram, com base em todos os parâmetros avaliados, indicar os genótipos BAFs 36, 55, 75, 102 como os de elevado potencial fisiológico. Particularmente nas condições de emergência a campo, a maioria dos genótipos apresenta ampla adaptação ambiental, com exceção dos BAFs 4, 7, 23. Pelo estudo de correlação, observou-se uma associação positiva entre o porcentual de germinação inicial com o comprimento de raiz primária e negativa com a massa de 100 sementes. Esta associação foi devido ao genótipo, o que permite indicar que os genótipos com menor massa de 100 sementes foram os mais vigorosos.
\end{abstract}

Termos para indexação: diversidade, vigor, condutividade elétrica, envelhecimento acelerado.

\section{PHYSIOLOGICAL POTENTIAL OF COMMON LANDRACE BEAN SEEDS (Phaseolus vulgaris L.)}

\begin{abstract}
The objective of this study was to characterize the physiologic potential of common landrace bean seeds. The seeds were produced in the 2007/2008 growing season with 26 genotypes from Lages-SC. The seed physiological potential was evaluated from the percentage germination, before and after accelerated ageing, the weight of 100 seeds, electrical conductivity, the length of the primary root and field emergence. The genotypes were grouped into classes using the Scott-Knott test and compared with a standard (commercial cultivars) using the Dunnett test, which indicated the BAFs 36, 55, 75, 102 genotypes as having a high physiological potential. Under field conditions, most landrace genotypes were adapted to environmental conditions, except for BAFs 4, 7, 23. The correlation analysis showed a positive association between the percentage initial germination and the length of the main root, and a negative correlation with the weight of 100 seeds. The genotypes with a lower seed mass showed more vigor.
\end{abstract}

Index terms: diversity, vigor, electrical conductivity, artificial ageing.

\footnotetext{
${ }^{1}$ Submetido em 05/10/2009. Aceito para publicação em 20/04/2010. Parte da pesquisa de PRODOC do primeiro autor realizada na UDESC-CAV, Lages, SC.

${ }^{2}$ Eng. Agr., Dr. em Ciências, Prof. Adjunto 1, Depto de Fitotecnia, Centro de Ciência agrárias/CCA, Universidade Federal de Santa Catarina/UFSC. Rua Admar Gonzaga, 1.346, Itacorubi, CEP: 88034-001, Florianópolis, CS. E-mail: cileide@cca.ufsc.br.

${ }^{3}$ Estudante de Agronomia, Departamento de Agronomia/DEAGRO, Centro de Ciências Agroveterinárias/CAV, Universidade do Estado de Santa
}

Catarina/UDESC. Caixa Postal 281, 88.502-970; Lages - SC.

${ }^{4}$ Eng. Agr., Dr. em Ciências, Prof. Associado, Dep de Agronomia/DEAGRO, Centro de Ciências Agroveterinárias/CAV, UDESC. Av. Luiz de Camões, 2090, 88520-000, Lages - SC - souza_clovis@cav.udesc.br.

${ }^{5}$ Eng. Agr., Dr. em Estatística, Departamento de Solos e Recursos Naturais, Centro de Ciências Agroveterinárias/CAV, Universidade do Estado de Santa Catarina/UDESC, 88520-000; Lages - SC - dmiquell@ cav.udesc.br. 


\section{INTRODUÇÃO}

No cultivo de feijão em Santa Catarina, nota-se que há um baixo uso de sementes melhoradas, pois é realizado em pequenas áreas, pouco tecnificadas, onde a agricultura familiar responde por $67 \%$ do feijão produzido no estado (ICEPA, 2004). A semente utilizada pelo agricultor advém de anos anteriores, as quais, normalmente são selecionadas pelo próprio agricultor por muitos anos, o que a caracteriza como semente crioula.

Para auxiliar o agricultor nesta seleção e manutenção deste recurso genético, existem pesquisadores que realizam a coleta e armazenamento de sementes em bancos de germoplasmas. Este armazenamento garante apenas que tal recurso não seja perdido ao longo dos anos, mas não viabiliza o uso destes genótipos de forma sustentável. Para indicar os genótipos mais promissores, e que de fato sejam considerados cultivar crioula é necessário conduzir estudos para diferenciá-las significativamente das cultivares comerciais, conforme a normativa da Lei de Sementes e Mudas 10.711/03 (Art. 2, inciso XVI). Neste caso, é importante considerar as características de produtividade, morfo-agronômicas, ciclo, resistência a pragas e doenças, qualidade tecnológica dos grãos como o menor tempo de cocção, maior teor e biodisponibilidade de nutrientes, entre outras características que já vem sendo conduzidas com os genótipos do Banco Ativo de germoplasma de Feijão do CAV-UDESC (Bordin et al., 2009; Coelho et al., 2007; Coelho et al., 2008; Pereira et al., 2009).

Além da necessidade e do interesse do agricultor, atualmente, já existe uma grande preocupação em incorporar tal diversidade encontrada nos genótipos crioulos nas cultivares comerciais, nos programas de melhoramento da cultura, principalmente no que se refere a características morfo-agronômicas, qualidade tecnológica e nutricional dos grãos (Carbonell et al., 2003; Coelho et al., 2007; Coelho et al., 2008; Pereira et al., 2009; Rodrigues et al., 2005).

Associado aos caracteres agronômicos e tecnológicos existe a necessidade de caracterizar o potencial fisiológico das sementes de feijão crioulo, o que potencializa o uso das sementes pelo agricultor e também pelos órgãos de pesquisa e programas de melhoramento da cultura do feijão, devido a sua ampla base genética. Sabe-se que o sucesso nos programas de melhoramento depende do uso de genitores superiores, não apenas em produtividade, resistência a doenças e insetos, ampla adaptação ambiental, mas também com características que os qualifiquem para produzir sementes de alta qualidade e assim garantir a produção de sementes em grande escala (Ramalho et al., 1993).

É importante salientar que um genótipo que apresente maior capacidade em translocar e armazenar nutrientes na semente tem maior potencial em produzir sementes com elevado poder germinativo e vigor de plântulas sob condições adversas de estresses bióticos e abióticos (Marcos Filho, 2005). No entanto, pouco se conhece a respeito da diversidade genética para estas características, e menos ainda para as sementes de genótipos crioulos de feijão.

Assim, o objetivo no trabalho foi caracterizar o potencial fisiológico da semente de feijão de genótipos crioulos com base no porcentual de germinação, vigor e comparadas com cultivares comerciais.

\section{MATERIAL E MÉTODOS}

As sementes dos genótipos crioulos foram produzidas em Lages, planalto sul de Santa Catarina, que possui $27^{\circ} 52^{\prime} 30^{\prime \prime}$ de latitude sul e $50^{\circ} 18^{\prime} 20^{\prime \prime}$ de longitude oeste, com altitude média de 930 m (EPAGRI, 2008).

Os lotes de sementes dos 26 genótipos foram provenientes do terceiro ano consecutivo de cultivo (safra 2007/2008). Na Tabela 1 é apresentada a identificação destes genótipos utilizados, provenientes da coleção do Banco Ativo de germoplasma de feijão (BAF) da Universidade do Estado de Santa Catarina (UDESC), em Lages, SC. A escolha dos 26 genótipos foi baseada em estudos prévios da diversidade genética quanto às características morfoagronômicas e de qualidade tecnológica de grãos (Coelho et al., 2007; Pereira et al., 2009).

O experimento para produção das sementes foi conduzido a campo, sob delineamento em blocos inteiramente ao acaso, com três repetições, em parcelas de quatro linhas de três metros, com 15 sementes por metro. A adubação de base foi realizada junto às linhas, previamente à semeadura, segundo análise do solo e recomendações descritas pela Comissão de Química e Fertilidade do Solo CQFS-RS/SC (2004). A adubação de cobertura foi realizada duas vezes, nos estádios de três e de cinco trifólios (V4 a V4-5), utilizando-se uma dosagem de $30 \mathrm{~kg} \cdot \mathrm{ha}^{-1}$ de N por hectare em cada aplicação. O controle de plantas daninhas e de pragas foi feito de acordo com as necessidades, utilizando-se os produtos químicos recomendados para a cultura.

Após a colheita, realizou-se a junção das sementes da seguinte forma: separou-se $500 \mathrm{~g}$ de semente colhidas das plantas da parte central de cada bloco perfazendo $1500 \mathrm{~g}$ e misturaram- 
se as sementes para obter uma amostra composta. Então se retirou uma amostra média de $600 \mathrm{~g}$ de onde foram obtidas as amostras de trabalho para realização dos diferentes testes (Brasil, 2009). As sementes da amostra média foram secas para $12 \%$ de umidade em estufa com circulação forçada do ar $\left(35^{\circ} \mathrm{C}\right)$ e foram armazenadas em câmara seca, com $30 \%$ a $40 \%$ de umidade relativa, e $8 \pm 1{ }^{\circ} \mathrm{C}$, até o momento das avaliações.

TABELA 1. Identificação, origem e nome comum dos genótipos crioulos e comerciais de feijão do Banco Ativo de feijão do CAV-UDESC.

\begin{tabular}{|c|c|c|c|}
\hline$* \mathrm{BAF}$ & Origem da coleção & Nome comum & Grupo comercial \\
\hline 03 & Palmitos (SC) & Manchinha & Cores \\
\hline 04 & Lages (SC) & Amendoim Lages & Cores \\
\hline 07 & Lages (SC) & Preto Lages & Preto \\
\hline 13 & Caxambú do Sul (SC) & Taquara & Preto \\
\hline 23 & Chapecó (SC) & Preto Chapecó & Preto \\
\hline 28 & Saudades (SC) & Vermelho saudades & Cores \\
\hline 36 & São José do Cerrito (SC) & Rasga & Preto \\
\hline 41 & Bom Jardim da Serra (SC) & Rosinha & Preto \\
\hline 42 & Capão Alto (SC) & Feijão Vagem Branca & Preto \\
\hline 44 & Capão Alto (SC) & Vermelho & Cores \\
\hline 46 & Lages (SC) & Sem Nome & Preto \\
\hline 47 & Piratuba (SC) & Preto precoce & Preto \\
\hline 50 & Lebon Régis (SC) & Carioca Brilhante & Carioca \\
\hline 55 & Cunha Porã (SC) & Preto & Preto \\
\hline 57 & Cunha Porã (SC) & Preto & Preto \\
\hline 68 & Lagoa Vermelha (RS) & Vermelho & Cores \\
\hline 75 & Formigueiro (RS) & Serrano & Preto \\
\hline 81 & Lebon Régis (SC) & Preto 70 dias & Preto \\
\hline 84 & Pinheiro Machado (RS) & Carioca rosado & Cores \\
\hline 97 & Iraí (RS) & Charque & Preto \\
\hline 102 & Goiânia CNPAF (GO) & México 309 & Preto \\
\hline 112 & IAPAR (PR) & IPR-88 Uirapurú & Preto \\
\hline 115 & EMBRAPA (GO) & BRS Valente & Preto \\
\hline 120 & Lages (SC) & Roxinho & cores \\
\hline 121 & IAPAR (PR) & Iapar 81 & carioca \\
\hline 192 & EMBRAPA (GO) & BRS Radiante & cores \\
\hline
\end{tabular}

*BAF = número da coleção no banco de germoplasma do CAV-UDESC, Santa Catarina, Brasil.

BAFs: 112 = Uirapuru; 115 = Valente; 121 = Iapar; 81, 192 = BRS Radiante, são cultivares comerciais.

O teste de germinação foi conduzido em papel toalha tipo Germitest, na forma de rolo, umedecido em água destilada na proporção de 2,5 vezes a massa do papel seco, com 50 sementes por repetição. As sementes permaneceram em germinador na posição vertical por 5 dias, na ausência de luz, sob temperatura de $25{ }^{\circ} \mathrm{C}$, conforme critérios das Regras para Análise de Sementes (Brasil, 2009). A contagem das sementes que germinaram e a medida da 
raiz primária foram realizadas aos 5 dias após a instalação do teste. $\mathrm{O}$ teste de envelhecimento acelerado foi realizado conforme a metodologia descrita por Marcos Filho (1987), onde se utilizaram 50 sementes por repetição distribuídas sob tela de inox fixada no interior da caixa plástica do tipo "gerbox ${ }^{\circledR}$ " contendo $40 \mathrm{~mL}$ de água destilada. As caixas foram tampadas e seladas com parafilm ${ }^{\circledR}$ e mantidas em câmara a $42{ }^{\circ} \mathrm{C}$, por 72 horas. Após este período foi realizado o teste de germinação e medidas do comprimento da raiz primária, sendo feita aos 5 dias após a instalação. O teste de condutividade elétrica foi feito apenas para as sementes recém-colhidas, em 50 sementes por repetição, com massa conhecida e acondicionadas em recipientes plásticos contendo $75 \mathrm{~mL}$ de água ultra pura (MilliQ), por um período de 24 horas, a $25^{\circ} \mathrm{C}$. Após as 24 horas procedeuse a leitura em condutivímetro (modelo MB-11P, Marte), com a expressão dos resultados em $\mu \mathrm{S} . \mathrm{cm}^{-1} . \mathrm{g}^{-1}$ de semente (Vieira, 1994).

As análises estatísticas foram realizadas de acordo com o delineamento experimental utilizado. Foram utilizados modelos lineares clássicos de análise da variância (Littel et al., 1991) e testados através do teste F (Steel et al., 1997). Para atenderem-se as pressuposições teóricas implícitas do referido teste, houve necessidade de se transformar a variável porcentagem de germinação elevando-se os seus valores unitários à potência $1 / 2$ e obtendo-se a seguir a função seno inversa (transformação arco-seno), conforme sugerido pela análise descritiva dos dados. Porém, os resultados são apresentados na escala original desta variável. A discriminação da variação entre os genótipos foi efetuada através do teste de Scott-Knott (1974). O grau de associação entre as variáveis foi avaliado através do coeficiente de correlação momento-produto de Pearson. Todas as análises foram conduzidas usando-se os procedimentos GLM e CORR do software $\mathrm{SAS}^{\circledR}$ (Statistical Analysis System) (SAS, 2003) e também se utilizando o software GENES (Cruz, 2008). Para todos os testes efetuados foi considerado o nível mínimo de significância de 5\%.

\section{RESULTADOS E DISCUSSÃO}

A análise de variância pelo teste $\mathrm{F}$ indicou diferenças significativas $(\mathrm{P}<0,01)$ entre os genótipos para variáveis: germinação, envelhecimento acelerado, comprimento de radícula, emergência em campo e testes de condutividade elétrica.

De acordo com o teste de Scott-Knott, observouse variação no porcentual de germinação entre os genótipos, cuja separação foi em seis classes distintas (Tabela 2). Sendo que os BAFs 7, 13, 36, 41, 55, 75, $81,84,102$ apresentaram maior valor em porcentual de germinação, entre 96 e 100\%. Os demais genótipos se dividiram entre outras cinco classes (Tabela 2). Os maiores porcentuais encontrados nos genótipos crioulos denotam a importância do potencial fisiológico destas sementes, visto que as sementes foram produzidas nas mesmas condições de campo e armazenadas também nas mesmas condições; além disto, apresentaram porcentual de germinação superior ao o mínimo exigido pelos padrões para a comercialização de sementes de feijão no Estado de Santa Catarina (80\%) (BRASIL-MAPA, 2005).

Quanto ao comprimento da raiz primária, os genótipos se agruparam em sete classes distintas, o que apresentou maior vigor obteve $11,35 \mathrm{~cm}$ de comprimento, e os menos vigorosos apresentaram valores entre 2,13 e 2,74 $\mathrm{cm}$ (Tabela 2). Contudo, a grande maioria dos genótipos crioulos se aproximaram das cultivares comerciais observadas por outros autores, em torno de $8 \mathrm{~cm}$ (Binotti et al., 2008), o que os qualificam como potencialmente vigorosas, e podem proporcionar maiores taxas de crescimento no período inicial de estabelecimento da cultura (Dutra et al., 2007).

A condutividade elétrica também foi variável entre os genótipos, pois se observou a separação de seis classes, com destaque para os BAFs 03 e 192, seguido pelos BAFs: $4,7,23,46,47,50,68$ os quais apresentaram menores valores, o que é um indicativo da maior integridade das membranas celulares e menor liberação de solutos. Pois, a baixa liberação de solutos após a semeadura, sob condições de campo pode provocar a menor perda de compartimentalização celular, além de minimizar o crescimento de microrganismos nocivos à emergência das plântulas (Marcos Filho, 2005). Ainda, segundo Marcos Filho (2005), o teste de condutividade elétrica tem se mostrado eficiente para a avaliação do vigor de sementes de várias espécies. Os resultados observados no presente trabalho corroboram no sentido de indicar o uso do método de condutividade elétrica também na qualificação do potencial fisiológico de sementes dentro da mesma espécie, ou seja, na diferenciação de genótipos ou linhagens. Este aspecto é particularmente interessante para os programas de melhoramento genético que visam incorporar características que favoreçam o desempenho fisiológico da semente de cultivares já melhoradas (Menten et al., 2006). 
TABELA 2. Peso de 100 sementes (PS), percentual de geminação (G), comprimento da raiz primária (CR) e condutividade elétrica inicial (CE) de sementes dos genótipos de feijão crioulos e comerciais.

\begin{tabular}{|c|c|c|c|c|c|c|c|c|c|c|}
\hline BAFs & PS (g) & $\mathrm{G}(\%)$ & 1 & 2 & $\mathrm{CR}(\mathrm{cm})$ & 1 & 2 & $\mathrm{CE}(\mu \mathrm{S} / \mathrm{cm} / \mathrm{g})$ & 1 & 2 \\
\hline 03 & 29,14 & 75 & $\mathrm{~d}$ & & 6,76 & $\mathrm{c}$ & $*$ & 39,60 & $f$ & $*$ \\
\hline 04 & 40,81 & 77 & $\mathrm{~d}$ & & 5,56 & d & & 51,83 & e & $*$ \\
\hline 07 & 17,61 & 96 & $\mathrm{a}$ & $*$ & 5,84 & d & & 49,64 & e & $*$ \\
\hline 13 & 22,23 & 99 & $\mathrm{a}$ & $*$ & 5,29 & $\mathrm{~d}$ & & 62,28 & $\mathrm{~d}$ & \\
\hline 23 & 22,80 & 85 & $\mathrm{c}$ & & 6,72 & $\mathrm{c}$ & $*$ & 54,49 & e & \\
\hline 28 & 27,94 & 94 & $\mathrm{~b}$ & & 6,02 & $\mathrm{~d}$ & $*$ & 66,34 & $\mathrm{~d}$ & \\
\hline 36 & 25,98 & 98 & $\mathrm{a}$ & $*$ & 6,26 & $d$ & $*$ & 89,51 & $\mathrm{~b}$ & $*$ \\
\hline 41 & 21,40 & 100 & $\mathrm{a}$ & $*$ & 11,35 & $\mathrm{a}$ & $*$ & 60,69 & $\mathrm{~d}$ & \\
\hline 42 & 17,32 & 77 & $\mathrm{~d}$ & & 5,04 & $\mathrm{e}$ & & 69,74 & $\mathrm{c}$ & \\
\hline 44 & 19,78 & 74 & $\mathrm{~d}$ & & 2,13 & $\mathrm{~g}$ & $*$ & 75,51 & $\mathrm{c}$ & \\
\hline 46 & 39,19 & 87 & $\mathrm{c}$ & & 7,55 & $\mathrm{~b}$ & $*$ & 51,45 & e & $*$ \\
\hline 47 & 38,85 & 89 & $\mathrm{~b}$ & & 6,17 & $\mathrm{~d}$ & $*$ & 47,09 & e & $*$ \\
\hline 50 & 20,45 & 89 & $\mathrm{~b}$ & & 5,97 & $\mathrm{~d}$ & & 55,32 & e & \\
\hline 55 & 18,43 & 97 & $\mathrm{a}$ & & 7,64 & b & $*$ & 66,40 & $\mathrm{~d}$ & \\
\hline 57 & 36,01 & 66 & $\mathrm{e}$ & $*$ & 4,34 & $\mathrm{e}$ & & 65,16 & $d$ & \\
\hline 68 & 51,51 & 58 & $\mathrm{e}$ & $*$ & 2,71 & $\mathrm{~g}$ & $*$ & 53,68 & $\mathrm{e}$ & $*$ \\
\hline 75 & 20,37 & 99 & $\mathrm{a}$ & $*$ & 6,75 & $\mathrm{c}$ & $*$ & 61,73 & $\mathrm{~d}$ & \\
\hline 81 & 17,04 & 98 & $\mathrm{a}$ & $*$ & 6,69 & $\mathrm{c}$ & $*$ & 72,19 & $\mathrm{c}$ & \\
\hline 84 & 19,59 & 99 & $\mathrm{a}$ & $*$ & 8,03 & $\mathrm{~b}$ & $*$ & 58,37 & $\mathrm{~d}$ & \\
\hline 97 & 47,01 & 65 & $\mathrm{e}$ & & 2,61 & $\mathrm{~g}$ & $*$ & 65,01 & $\mathrm{~d}$ & \\
\hline 102 & 25,73 & 99 & $\mathrm{a}$ & $*$ & 4,82 & $\mathrm{e}$ & & 72,17 & $\mathrm{c}$ & \\
\hline 112 & 21,90 & 85 & $\mathrm{c}$ & & 4,66 & $\mathrm{e}$ & & 89,64 & $\mathrm{~b}$ & $*$ \\
\hline 115 & 15,21 & 80 & $\mathrm{~d}$ & & 3,44 & $\mathrm{f}$ & & 65,90 & $\mathrm{~d}$ & \\
\hline 120 & 64,68 & 37 & $\mathrm{f}$ & $*$ & 3,24 & $\mathrm{f}$ & $*$ & 124,00 & $\mathrm{a}$ & $*$ \\
\hline 121 & 24,72 & 72 & $\mathrm{~d}$ & & 2,74 & $\mathrm{~g}$ & $*$ & 91,20 & $\mathrm{~b}$ & $*$ \\
\hline 192 & 54,41 & 91 & $\mathrm{~b}$ & & 3,63 & $\mathrm{f}$ & & 33,93 & $\mathrm{f}$ & $*$ \\
\hline
\end{tabular}

${ }^{1}$ Médias seguidas pelas mesma letra, em cada coluna, pertencem a mesma classe, conforme o teste Scott-Knott, em nível de 5\% de probabilidade.

2* Indica diferença significativa pelo teste Dunnett (nível de 5\% de probabilidade).

Ao comparar os genótipos crioulos com as cultivares, pelo teste de Dunnett, verificou-se que alguns genótipos crioulos (BAFs 41, 84, 75, 81, 36) se destacaram significativamente superiores ao BAF 112 (testemunha), tanto para o porcentual de germinação como para o comprimento da raiz primária (Tabela 2). O que potencializa tais genótipos para serem considerados para características relacionadas à qualidade de sementes. Quanto ao teste de condutividade elétrica, observou-se que os BAFs $68,4,46$, $7,47,3,192$ apresentaram menores valores em relação à testemunha (BAF 115), e apesar de não serem coincidentes com os citados anteriormente também merecem especial atenção visto que o teste de condutividade nem sempre tem correlação alta com o porcentual de germinação e comprimento da raiz primária e sim com o fato de maior tempo de envelhecimento acelerado ter afetado negativamente a germinação e o vigor das sementes (Binotti et al., 2008).

Após a submissão das sementes ao envelhecimento acelerado, observou-se um decréscimo acentuado tanto no porcentual de germinação como no comprimento da raiz primária em função do estresse causado por elevada 
temperatura e umidade. Contudo, as respostas foram diferentes entre os genótipos, o que permitiu detectar o efeito do genótipo sobre o vigor das sementes.

Quanto ao porcentual de germinação, observou-se a separação dos genótipos em seis classes, sendo que o maior número de genótipos apresentou porcentual de germinação inferior a $39 \%$, e apenas os BAFs $36,44,55$, $75,97,102$ se destacaram com porcentual superior a $51 \%$, com especial atenção para o BAF 192, o qual teve $91 \%$ de germinação (Tabela 3).

TABELA 3. Percentual de geminação (G), comprimento da raiz primária (CR) de sementes dos genótipos de feijão crioulos e comerciais após envelhecimento acelerado, e emergência a campo (EC).

\begin{tabular}{|c|c|c|c|c|c|c|c|c|c|}
\hline BAFs & G (\%) & 1 & 2 & $\mathrm{CR}(\mathrm{cm})$ & 1 & 2 & EC (\%) & 1 & 2 \\
\hline 03 & 31 & $\mathrm{~d}$ & & 3,81 & $\mathrm{a}$ & & 82 & $\mathrm{c}$ & $*$ \\
\hline 04 & 23 & d & & 1,27 & $\mathrm{c}$ & & 76 & $\mathrm{c}$ & * \\
\hline 07 & 51 & $\mathrm{~b}$ & $*$ & 1,56 & $\mathrm{c}$ & & 75 & $\mathrm{c}$ & \\
\hline 13 & 27 & d & & 2,66 & $\mathrm{~b}$ & & 89 & $\mathrm{a}$ & $*$ \\
\hline 23 & 39 & $\mathrm{c}$ & & 4,76 & $\mathrm{a}$ & & 74 & $\mathrm{c}$ & * \\
\hline 28 & 13 & e & & 2,45 & $\mathrm{~b}$ & & 80 & $\mathrm{c}$ & $*$ \\
\hline 36 & 52 & $\mathrm{~b}$ & $*$ & 4,12 & $\mathrm{a}$ & & 80 & $\mathrm{c}$ & $*$ \\
\hline 41 & 17 & $\mathrm{e}$ & & 2,36 & $\mathrm{~b}$ & & 89 & $\mathrm{a}$ & $*$ \\
\hline 42 & 6 & $\mathrm{f}$ & $*$ & 0,69 & $\mathrm{c}$ & $*$ & 80 & $\mathrm{c}$ & $*$ \\
\hline 44 & 51 & $\mathrm{~b}$ & $*$ & 2,98 & $\mathrm{~b}$ & & 83 & $\mathrm{~b}$ & \\
\hline 46 & 29 & $\mathrm{~d}$ & & 1,88 & $\mathrm{c}$ & & 94 & $\mathrm{a}$ & \\
\hline 47 & 36 & d & & 2,79 & $\mathrm{~b}$ & & 87 & $\mathrm{~b}$ & \\
\hline 50 & 13 & $\mathrm{e}$ & & 2,43 & $\mathrm{~b}$ & & 89 & $\mathrm{a}$ & \\
\hline 55 & 55 & $\mathrm{~b}$ & $*$ & 2,87 & $\mathrm{~b}$ & & 86 & $\mathrm{~b}$ & \\
\hline 57 & 3 & $\mathrm{f}$ & $*$ & 1,17 & $\mathrm{c}$ & & 91 & $\mathrm{a}$ & \\
\hline 68 & 32 & d & & 2,23 & $\mathrm{~b}$ & & 87 & $\mathrm{~b}$ & \\
\hline 75 & 55 & $\mathrm{~b}$ & $*$ & 2,17 & $\mathrm{~b}$ & & 86 & $\mathrm{~b}$ & \\
\hline 81 & 24 & d & & 2,62 & $\mathrm{~b}$ & & 87 & $\mathrm{~b}$ & \\
\hline 84 & 14 & $\mathrm{e}$ & & 1,90 & $\mathrm{c}$ & & 85 & $\mathrm{~b}$ & \\
\hline 97 & 55 & $\mathrm{~b}$ & $*$ & 4,97 & $\mathrm{a}$ & & 88 & $\mathrm{a}$ & \\
\hline 102 & 60 & $\mathrm{~b}$ & $*$ & 1,41 & $\mathrm{c}$ & & 91 & $\mathrm{a}$ & \\
\hline 112 & 26 & $\mathrm{~d}$ & & 2,89 & $\mathrm{~b}$ & & 90 & $\mathrm{a}$ & \\
\hline 115 & 23 & d & & 3,21 & $\mathrm{~b}$ & & 85 & $\mathrm{~b}$ & \\
\hline 120 & 5 & $\mathrm{f}$ & $*$ & 2,39 & $\mathrm{~b}$ & & 86 & $\mathrm{~b}$ & \\
\hline 121 & 20 & $\mathrm{~d}$ & & 1,01 & $\mathrm{c}$ & $*$ & 80 & $\mathrm{c}$ & \\
\hline 192 & 91 & $\mathrm{a}$ & $*$ & 4,79 & $\mathrm{a}$ & & 87 & $\mathrm{~b}$ & \\
\hline
\end{tabular}

${ }^{1}$ Médias seguidas pelas mesma letra, em cada coluna, pertencem a mesma classe, conforme o teste Scott-Knott, em nível de 5\% de probabilidade.

2* Indica diferença significativa pelo teste Dunnett (nível de 5\% de probabilidade).

O comprimento da raiz primária também foi afetado diferentemente entre os genótipos, mas a divisão foi apenas em três classes distintas. Com maiores valores para os BAFs 3, 23, 36, 97, 192, que apresentaram entre 3,81 e 4,97 cm, ou seja, inferiores aos observados na avaliação inicial das sementes (Tabela 3 e Tabela 2).

$\mathrm{O}$ potencial positivo dos genótipos quanto as características de vigor foi evidenciado ao compará-los com a testemunha (BAF 115), onde se constatou que os BAFs 7, 36, $42,44,55,57,75,97,102$ apresentaram valores superiores no 
porcentual de germinação mesmo depois de submetidos ao envelhecimento acelerado (Tabela 3). Além disto, a maioria dos genótipos que apresentaram uma emergência a campo superior a $80 \%$ foram coincidentes com a maioria dos que apresentaram germinação inicial superior a 96\% (Tabela 2) e germinação após o envelhecimento precoce superior a $50 \%$ (Tabela 3) o que permitiu destacar os BAFs 7, 36, $55,75,102$ com elevado potencial fisiológico de sementes. Mas, se for considerado também o porcentual mínimo de emergência a campo exigido para a comercialização de sementes $(80 \%)$, a grande maioria dos genótipos se enquadraram nesta exigência, com exceção dos BAFs 4, 7, 23. Nas condições de campo, foi possível constatar a eficiência dos genótipos na adaptação ao ambiente, o que é justificado devido a interação entre sua ampla base genética (Pereira et al., 2009) e condições ambientais favoráveis para germinação. No caso de genótipos comerciais, Salum et al. (2008) observaram que a imposição de restrições nutricionais durante o cultivo afeta pouco a qualidade fisiológica das sementes.

O grau de associação entre as variáveis analisadas foi determinado pelo coeficiente de correlação momentoproduto de Pearson. Neste caso, observou-se maior correlação entre germinação e comprimento de raiz primária $(\mathrm{r}=+0,63)$, isto indica que na maioria dos genótipos o maior porcentual de germinação indicou maior comprimento de raiz primária. Já com relação à condutividade elétrica constatou-se uma correlação negativa com o porcentual de germinação $(r=-0,25)$ e com o comprimento da raiz primária $(\mathrm{r}=-0,28)$, ou seja isto indica que quanto maior a germinação e comprimento de raiz primária menor os danos sobre a integridade das membranas. Entretanto, isto não pode ser considerado uma regra, ao considerar os baixos valores absolutos da correlação. O elevado grau de associação $(r=+0,51)$ entre a capacidade de germinação e o comprimento da raiz primária foi mantido após o envelhecimento acelerado das sementes, o que enfatiza o uso destas variáveis em estudos de diferenciação do potencial fisiológicos de sementes, como já indicado por outros autores (Binotti et al., 2008; Marcos Filho, 2005).

Ao correlacionar a diversidade no peso de 100 sementes (Tabela 2) com o porcentual de germinação inicial, observouse uma alta correlação negativa $(\mathrm{r}=-0,65)$, ou seja, quanto menor a semente, maior foi o porcentual de germinação, este efeito negativo está diretamente relacionado como o genótipo avaliado, visto que o tamanho de sementes é uma característica pouco influenciada pelo ambiente. $\mathrm{O}$ mesmo efeito já foi observado por outros autores, mas com cultivares comerciais (Jauer et al., 2002). Contudo, a germinação pode ter correlação positiva com o tamanho da semente, este efeito foi considerado ao avaliar sementes do mesmo genótipo e mesmo lote, as sementes pequenas $(<6$ $\mathrm{mm}$ de diâmetro) apresentaram germinações menores que $62 \%$ (Carvalho e Nakagawa, 2000).

Além da massa de sementes contribuir na seleção de genótipos para potencial fisiológico de sementes, observou-se em trabalhos prévios que é possível selecionar simultaneamente para melhor qualidade culinária, pois genótipos com menor massa de grãos de feijão apresentaram menor tempo de cocção (Coelho et al., 2009).

Pelas características avaliadas, constatou-se o potencial fisiológico das sementes crioulas, particularmente ao compará-las com as cultivares comerciais. Neste caso, os genótipos crioulos foram favorecidos em função da ampla base genética e da facilidade de adaptação às condições ambientais, ao contrário das cultivares comerciais que são consideradas linhagens de estreita base genética.

\section{CONCLUSÕES}

As sementes das cultivares de feijão crioulo apresentam elevado potencial fisiológico em relação a cultivar comercial, em função do maior porcentual inicial de germinação, maior comprimento de raiz primaria, baixos valores de condutividade, elevada emergência a campo, particularmente os BAFs 36, 55, 75, 102.

O estudo de correlação indicou associação positiva entre o porcentual de germinação inicial e o comprimento de raiz primária e negativa com a massa de 100 sementes, o que permitiu indicar que os genótipos com menor massa de 100 sementes foram os mais vigorosos.

\section{AGRADECIMENTOS}

O primeiro autor agradece a CAPES (Coordenação de Aperfeiçoamento de Pessoal de Nível Superior) pelo apoio financeiro via PRODOC (Programa de Apoio a Projetos Institucionais).

\section{REFERÊNCIAS}

BINOTTI, F.F.S.; HAGA, K.I.; CARDOSO, E.D.; ALVES, C.Z.; SÁ, M.E.; ARF, O. Efeito do período de envelhecimento acelerado no teste de condutividade elétrica e na qualidade fisiológica de sementes de feijão. Acta Scientiarum. Agronomy, v.30, n.2, p.247-254, 2008.

BORDIN, L.C.; COELHO, C.M.M.; SOUZA, C.A.; ZILIO, 
M. Diversidade genética para a padronização do tempo e percentual de hidratação preliminar ao teste de cocção de grãos de feijão. Ciência e Tecnologia de Alimentos, 2010. No prelo.

BRASIL. Ministério da Agricultura, Pecuária e Abastecimento. Regras para análise de sementes. Ministério da Agricultura, Pecuária e Abastecimento. Secretaria de Defesa Agropecuária. Brasília, DF: MAPA/ ACS, 2009. 395p.

BRASIL. Ministério da Agricultura, Pecuária e Abastecimento. Instrução Normativa 25/2005, de 16 de dezembro de 2005, Ministério da Agricultura, Pecuária e do Abastecimento (Anexo V - Padrões para produção e comercialização de sementes de feijão). Brasília, DF: SNAD/ DNDN/CLAV: Diário Oficial da União, Brasília,DF, 20 dez. 2005, p. 18, Seção 1.

CARBONELL, S.A.M.; CARVALHO, C.R.L.; AZEVEDO FILHO, J.A., de; SARTORI, J.A. Qualidade tecnológica de grãos de genótipos de feijoeiro cultivados em diferentes ambientes. Bragantia, v.62, n.3, p.369-379, 2003.

CARVALHO, N.M.; NAKAGAWA, J. Sementes: ciência, tecnologia e produção. 4.ed. Jaboticabal: FUNEP, 2000. $588 \mathrm{p}$.

COELHO, C.M.M.; COIMBRA, J.L.M.; SOUZA, C.A.; BOGO, A.; GUIDOLIN, A.F. Diversidade Genética em acessos de feijão (Phaseolus vulgaris L.). Ciência Rural, v.37, n.5, p.1241-1247, 2007.

COELHO, C.M.M.; SCHMIDT, D.; ZÍLIO, M. Efeito da massa dos grãos de feijão (Phaseolus vulgaris L.) no menor tempo de cocção. Magistra, v.22, n.2, 2009.

COELHO, C.M.M.; SOUZA, C.A.; DANELLI, A.L.D.; PEREIRA, T.; SANTOS, J.C.P.; PIAZZOLI, D. Capacidade de cocção de grãos de feijão em função do genótipo e da temperatura da água de hidratação. Ciência e Agrotecnologia, v.32, n.4, p.1080-1086, 2008.

CQFS-RS/SC. Manual de adubação e de calagem para os estados do Rio Grande do Sul e Santa Catarina. Porto Alegre: SBCS - Núcleo Regional Sul/UFRGS, 2004. 400p.

CRUZ, C.D. Programa genes - diversidade genética. Viçosa-MG: UFV, 2008. 278p.

DUTRA, A.S.; TEÓFILO, E.M.; MEDEIROS FILHO, S.; DIAS, F.T.C. Qualidade fisiológica de sementes de feijão caupi em quatro regiões do estado do Ceará. Revista Brasileira de Sementes, v.29, n.2, p.111-116, 2007.

EPAGRI. Atlas climatológico do estado de Santa Catarina. Online. Florianópolis: Disponível em: $<$ http://ciram.epagri. rct-sc.br> Acesso em 20 abr. 2009.

ICEPA. Síntese anual da agricultura de Santa Catarina. Florianópolis: Instituto CEPA, 2004. 377p.

JAUER, A.; MENEZES, N.L.de.; GARCIA, D.C. Tamanho das sementes na qualidade fisiológica de cultivares de feijoeiro comum. Revista da FZVA, v.9, n.1, p.65-72, 2002.

LITTEL, R.C.; FREUND, R.J.; SPECTOR, P.C. SAS System for Linear Models. 3.ed. Cary, NC, USA: SAS Institute Inc, 1991. 329p.

MARCOS FILHO, J. Fisiologia de sementes de plantas cultivadas. Piracicaba: FEALQ, 2005. 495p.

MARCOS FILHO, J.; CICERO, S.M.; SILVA, W.R. Avaliação da qualidade de sementes. Piracicaba: FEALQ, 1987. 230p.

MENTEN, J.O.M.; MORAES, M.H.D.; NOVEMBRE, A.D.L.C.; ITO, M.A. Qualidade das sementes de feijão no Brasil. Artigo em Hypertexto: Disponível em: $<\mathrm{http}$ ://www. infobibos.com/Artigos/2006_2/SementesFeijao/index.htm> Acesso em 27 abr. 2009, 2006.

PEREIRA, T.; COELHO, C.M.M.; BOGO, A.; GUIDOLIN, A.F.; MIQUELLUTI, D.J. Diversity in common bean landraces from South-Brazil. Acta Botanica Croatica, v.68, n.1, p.79-92, 2009.

RAMALHO, M.A.P.; Dos SANTOS, J.B.;ZIMMERMANN, M.J.O. Genética quantitativa de plantas autógamas: aplicações ao melhoramento do feijoeiro. Goiânia: UFG, 1993. 271p.

RODRIGUES, J.D.A.; RIBEIRO, N.D.; CARGNELUTTI FILHO, A.; TRENTIN, M.; LONDERO, P.M.G. Qualidade para o cozimento de grãos de feijão obtidos em diferentes épocas de semeadura. Bragantia, v.64, n.3, p.369-376, 2005.

SALUM, J.D.; ZUCARELI, C.; GAZOLA, E.; NAKAGAWA, J. Características químicas e fisiológicas de sementes de feijão em função do teor de fósforo na semente e doses de fósforo no solo. Revista Brasileira de Sementes, v.30, p.140-149, n.1, 2008. 
SAS. SAS Institute Inc ${ }^{\circledR}$ 2003. Cary, NC, USA, Lic. UDESC: SAS Institute Inc, 2003.

SCOTT, A.J.; KNOTT, M. A cluster analysis methods for grouping means in the analysis of variance. Biometrics, v.30, n.3, p.507-512, 1974.

STEEL, R.G.D.; TORRIE, J.H.; DICKEY, D.A. Principles and procedures of statistics - a biometrical approach. 3.ed. New York, USA: McGraw-Hill, 1997. 666p.

VIEIRA, R.D. Teste de condutividade elétrica. In: VIEIRA, R.D.; CARVALHO, N.M. (Ed.). Testes de vigor em sementes. Jaboticabal: FUNEP, 1994. p.103-132. 